\title{
PENEGAKAN HUKUM ADMINISTRASI TERHADAP KEGIATAN YANG TIDAK BERDAMPAK PENTING YANG BELUM MEMILIKI DOKUMEN

\author{
UKL-UPL (Studi PT. Hadi Putra Makmur Kota Semarang)
}

\author{
Istiqomah \\ Fakultas Hukum, Universitas Stikubank (UNISBANK) Semarang \\ E-mail : istiqomah97.ma@gmail.com
}

\begin{abstract}
ABSTRAK
Izin lingkungan adalah izin yang diberikan kepada setiap orang atau pemrakarsa yang ingin melakukan usaha dan/atau kegiatan yang wajib UKL-UPL dalam rangka perlindungan dan pengelolaan lingkungan hidup sebagai syarat memperoleh izin usaha dan/atau kegiatan. Pelanggaran yang dilakukan oleh PT. Hadi Putra Makmur terkait masalah kewajiban dan larangan, khususnya mengenai perizinan, upaya pngelolaan dan pemantauan lingkungan hidup, dengan ini pihak pengawasan dari DLH menegakan dengan cara pemberian sanksi administrasi. Hal tersbut diatas yang menjadi dasar penulis mengambil judul "PENEGAKAN HUKUM ADMINISTRASI TERHADAP KEGIATAN YANG TIDAK BERDAMPAK PENTING YANG BELUM MEMILIKI DOKUMEN UKL-UPL (Studi PT. Hadi putra Makmur Kota Semarang)".Didalam penelitian ini, penulis mengangkat permasalahan, yaitu: a. Bagaimana penegakan hukum administrasi terhadap kegiatan yang tidak berdampak penting yang belum memiliki dokumen UKL-UPL? b. Bagaimana hambatan yang timbul dalam penegakan hukum administrasi terhadap kegiatan yang tidak berdampak penting yang belum memiliki dokumen UKL-UPL? c. Bagaimana Peran Hukum Administrasi Dalam Penegakan Hukum Lingkungan ?Metode yang digunakan adalah dengan menggunakan tipe penelitian yuridis normatif dengan spesifikasi penelitian deskriptif analitis, sumber data sekunder dengan metode pengumpulan data melalui studi pustaka dan wawancara, dan metode penyajian dan metode analisis data menggunakan metode deskriptif analitis.Tujuan penelitian ini menjelaskan penerapan sanksi administrasi terhadap kegiatan yang tidak berdampak penting yang belum memiliki dokumen UKL-UPL. Hambatan yang timbul dalam penegakan sanksi administrasi terhadap kegiatan yang tidak berdampak penting yang belum memiliki dokumen UKL-UPL, dan peran hukum administrasi dalam penegakan hukum lingkungan. Hasil penelitian bahwa PT. Hadi Putra Makmur telah melakukan pelanggaran mengenai perizinan, upaya pengelolaan dan pemantauan lingkungan hidup, DLH kota Semarang telah memberikan sanksi administrasi berupa paksaan pemerintah sesuai dengan PP no. 37 Tahun 2012 tentang izin lingkungan. Sanksi administrasi merupakan instrumen hukum yang digunakan pertama kali oleh DLHdalam penegakan kasus yang dilakukan olehPT. Hadi Putra Makmur.
\end{abstract}

Kata kunci : Penegakan Administrasi, Izin Lingkungan, UKL-UPL 


\begin{abstract}
An environmental permit is a permit given to any person or initiator who wishes to undertake a business and / or activity that is required to be UKL-UPL in the framework of environmental protection and management as a condition of obtaining a business and / or activity license. Violations committed by PT. Hadi Putra Makmur related to the issue of obligations and prohibitions, especially regarding licensing, efforts to manage and monitor the environment, hereby the supervision of DLH enforces by giving administrative sanctions. The above is the basis for the author to take the title "ADMINISTRATIVE LAW ENFORCEMENT ON IMPORTANT ACTIVITIES THAT DO NOT HAVE DOCUMENTS UKL-UPL (Study of PT. Hadi Putra Makmur Semarang City)." In this research, the authors raise the problems, namely: a. How is administrative law enforcement for activities that have no significant impact that do not yet have UKL-UPL documents? $b$. What are the obstacles that arise in the administration of administrative law for activities that do not have significant impacts that do not have UKL-UPL documents? c. What is the Role of Administrative Law in Enforcement of Environmental Law? The method used is to use the type of juridical normative research with descriptive analytical research specifications, secondary data sources with data collection methods through literature study and interviews, and the method of presentation and data analysis methods using descriptive analytical methods. The purpose of this study is to explain the application of administrative sanctions for activities that do not have significant impacts that do not have UKL-UPL documents. Barriers that arise in the enforcement of administrative sanctions for activities that do not have a significant impact that do not have UKL-UPL documents, and the role of administrative law in environmental law enforcement. The results showed that PT. Hadi Putra Makmur has violated licensing, environmental management and monitoring efforts, DLH Semarang city has imposed administrative sanctions in the form of government coercion in accordance with PP no. 37 of 2012 concerning environmental permits. Administrative sanctions are legal instruments used for the first time by DLH in enforcing cases conducted by PT. Hadi Putra Makmur.
\end{abstract}

Keywords: Administrative Enforcement, Environmental Permit, UKL-UPL 


\section{Pendahuluan}

Lingkungan hidup merupakan kesatuan ruang dengan semua benda, termasuk manusia dan perilkunya yang mempengaruhi kelangungan kehidupan dan kesejahteraan manusia serta makhluk hidup lainnya. Aktivitas pembangunan yang dilakukan dalam berbagai bentuk Usaha dan/atau Kegiatan pada dasarnya akan menimbulkan dampak terhadap lingkungan berupa pencemaran. Altivitas pembangunan dianalisis sejak awal perencanaan sebagai pedoman untuk meminimalisir dampak yang akan ditimbulkan dari proses pembangunan. Penegndalian dampak negatif dan pengembangan dampak positif dapat di terapkan sebelum diadakannya pembangunan dengan diterapkan prinsip berkelanjutan dan berwawasan lingkungan dalam proses pelaksanaan pembangunan.

Proses pembangunan yang dilakukan oleh pemrakarsa atau pelaku usaha yang ingin melakukan pembangunan harus memiliki izin lingkungan terlebih dahulu sesuai dengan UU Nomor 32 Tahun 2009 tentang Perlindungan dan Pengelolaan Lingkungan Hidup dan PP Nomor 27 Tahun 2012 tentang Izin Lingkungan. Izin lingkungan diberikan kepada permrakarsa yang ingin melakukan suatu kegiatan dan/atau usaha yang wajib UKL-UPL dalam rangka perlindungan dan pengelolaan lingkungan hidup, juga sebagai syarat untuk mendapatkan izin usaha. Izin lingkungan diberikan kepada pemerintah dan pelaku usaha sebagai instrumen atau pedoman untuk pencegahan kerusakan dan/atau pencemaran lingkungan hidup serta untuk meminimalisir dampak yang akan ditimbulkan dari proses pembanguan. Dalam pasal 71 ayat (1) PP tentang Izin Lingkungan menjelaskan bahwa pemegang Izin Lingkungan yang tidak memiliki izin lingkungan akan dikenakan sanksi administratif. Sanksi administratif menurut pasal 76 UUPPLH dibedakan menjadi empat jenis sanksi, yaitu : teguran tertulis, paksaan pemerintah pembekuan izin lingkungan, dan pencabutan izin lingkungan.

Berdasarkan uraian dari latar belakang diatas maka dapat ditarik beberapa rumusan masalah yaitu sebagai berikut :

1. Bagaimana penegakan hukum administrasi terhadap kegiatan yang tidak berdampak penting yang belum memiliki dokumen UKL-UPL ?

2. Bagaimana hambatan yang timbul dalam penegakan hukum administrasi terhadap kegiatan yang tidak berdampak penting yang belum memiliki dokumen UKL-UPL?

3. Bagaimana Peran Hukum Administrasi Dalam Penegakan Hukum Lingkungan?

Metode Penelitian

Penelitian

tentang

"PENEGAKAN

HUKUM

ADMINISTRASI

TERHADAP

KEGIATAN YANG TIDAK

BERDAMPAK PENTING YANG

BELUM MEMILIKI DOKUMEN

UKL-UPL (Studi PT. Hadi Putra 
Makmur Kota Semarang)" ini merupakan suatu penelitian hukum dengan menggunakan metode pendekatan yuridis normatif.

Fokus penelitian menggunakan penelitian yang deskriptif analitis. Penelitian diskriptif analitis merupakan penelitian yang dilakukan dengan melukiskan objek penelitian berdasarkan peraturan perundang undangan dan bertujuan memberikan gambaran suatu obyek yang menjadi masalah dalam penelitian.

Data yang dikumpulkan adalah data yang berhubungan dengan peraturan perundang-undangan yang berlaku yakni Undang-Undang Nomor 32 Tahun 2009 tentang Perlindungan dan Pengelolaan Lingkungan Hidup, Peraturan Pemerintah Nomor 27 Tahun 2012 Tentang Izin Lingkungan serta akan ditinjau pula dengan teoriteori yang berkaitan di dalam hukum lingkungan, serta pengumpulan data dalam penelitian ini menggunakan studi pustaka dan wawancara.

\section{Pembahasan}

1. Penegakan Sanksi Administrasi Terhadap Kegiatan Yang Tidak Berdampak Penting Yang Belum Memiliki Dokumen UKL-UPL

Dalam studi PT. Hadi Putra Makmur selaku penanggung jawab kegiatan usaha Guest House Siliwangi (penginapan) berdasarkan pengawasan dan hasil verifikasi yang telah dilakukan oleh Dinas Lingkungan Hidup Kota Semarang menemukan pelanggaran terhadap peraturan perundang-undangan dibidang perizinan dan kerusakan lingkungan hidup, bahwa PT. Hadi Putra Makmur ini tidak melengkapi izin lingkungan sebagaimana tercantum dalam PP Nomor 27 Tahun 2012 tentang izin lingkungan.

Penerapan sanksi administrasi yang digunakan oleh Dinas Lingkungan Hidup (DLH) Kota Semarang terhadap Guest House Siliwangi Kota Semarang yang bergerak di bidang jasa penginapan pada dasarnya sesuai dengan Peraturan Menteri Lingkungan Hidup No. 2 tahun 2013 mengenai Jenis-jenis Sanksi Administratif dan juga memiliki pengertian yang sama dengan UU No. 32 Tahun 2009 dan Peraturan Pemerintah No. 27 tahun 2012 tentang Izin Lingkungan. Membedakan jenis-jenis sanksi administrasi dibedakan menjadi 4 yang meliputi sanksi:

a) Teguran tertulis, diberikan apabila pelanggaran yang dilakukan secara tata kelola lingkungan hidup dalam kategori baik, secara tekhnis masih dapat dilakukan perbaikan dan belum menimbulkan dampak negatif terhadap lingkungan hidup.

b) Paksaan pemerintah, diberikan setalah adanya teguran tertulis atau tanpa teguran tertulis apabila pelanggaran yang dilakuka menimbulkan ancaman yang sangat serius bagi menusia dan lingkungan hidup, 
dampak yang lebih besar dan lebih luas jika tidak segera ditangani, dan kerugian yang lebih besar.

c) Pembekuan izin lingkungan, diterapkan apabila pemrakarsa atau pelaku usaha tidak melaksanakan paksaan pemerintah, melakukan kegiatan selain kegiatan yang tercantum dalam izin lingkungan dan pemegang izin lingkungan belum menyelesaikan secara tekhnis apa yang searusnya menjadi kewajibannya.

d) Pencabutan izin lingkungan diterapkan terhadap pelanggaran tidak melaksanakan sanksi berupa paksaan pemerintah, memindahtangankan izin usaha kepada pihak lain tanpa persetujuan dari pemberi izin usaha, tidak melaksanakan sebagian besar sanksi administrasi yang diterapkan dalam waktu tertentu, danterjadinya pelanggaran serius terhadap lingkungan yang mengakibatkan pencemaran dan/atau kerusakan yang relatif besar.

e) Denda administratif diberikan kepada pemrakarsa atau pelaku usaha karena terlambat untuk melaksanakan paksaan pemerintah.

Di dalam penegakan yang dilakukan oleh Dinas Lingkungan Hidup terhadap Guest House Siliwangi yaitu menggunakan sanksi administrasi dengan jenis yang kedua berupa paksaan pemerintah. Paksaan pemerintah diterapkan kepada penanggung jawab usaha dan/atau kegiatan dalam hal telah melakukan pelanggaran peraturan perundangundangan dan persyaratan yang di tentukan dalam izin lingkungan. Paksaan pemerintah ini dapat dijatuhkan dengan teguran tertulis atau tanpa teguran tertulis terlebih dahulu. Persyaratan yang belum dilakukan sebelumnya adalah belum dibuatnya dokumen izin lingkungan hidup terhadap usaha Guest House Siliwangi tersebut sehingga mewajibkan penanggung jawab untuk mematuhi sanksi yang telah di berikan oleh Dinas Lingkungan Hidup (DLH) Kota Semarang. Paksaan pemerintah tersebut diberikan karena berdasarkan pasal 80 UUPPLH pelanggaran yang dilakukan menimbulkan ancaman, dampak, dan kerugian yang serius bagi manusia dan lingkungan hidup jika tidak segera dihentikan pencemaran dan/atau perusakannya.

Paksaan pemerintah yang diberikan oleh Dinas Lingkungan Hidup (DLH) yang dilakukan oleh bidang pengawasan yang mempunyai tugas dan fungsi pokok untuk melakukan pengawasan dan pembinaan kepada Guest House Siliwngi Semaranng mendapat respon yang cukup baik. Dasar hukum umum pengawasan sebagai sarana penegakan hukum lingkungan 
administratif dalam pengendalian pencemaran lingkungan adalah Pasal 71-75 UU PPLH.

Paksaan pemerintah yang diberikan kepada PT. Hadi Putra Makmur pelaku usaha diberikan tanpa teguran tertulis terlebih dahulu, karena pelanggaran yang ditimbulkan menimbulkan dampak dan kerugian yang lebih besar bagi lingkungan hidup. Dengan ini PT. Hadi Putra Makmur diminta untuk menyusun dokumen Upaya Pemantauan Lingkungan dan Upaya Pengelolaan Linghkungan (UKL-UPL) yang berisi tentang hal-hal seperti pengelolaan terhadap dampak lingkungan hidup, upaya pengelolaan lingkungan, dan upaya pemtauan lingkungan.

2. Hambatan Yang Timbul Dalam Penegakan Sanksi Administrasi Terhadap Kegiatan Yang Tidak Berdampak Penting Yang Belum Memiliki Dokumen UKL-UPL

Dalam penegakan hukum adminisstrasi lingkungan hidup oleh Dinnas Lingkungan Hidup kota Semarang terhadap PT. Hadi Putra Makmur selaku penanggng jawab kegiatan usaha Guest House Siliwangi (penginapan) Kota Semarang ada bebrapa hambatan yang tmbul di dalam penegakannya yang mengakibatkan tiddak efektivitasnya faktor pendukungg dalam penegakan hukum lingkungan. Faktor penghambat tersebut meliputi:
1. Faktor Internal

Banyak peraturan-perauran yang dikeluarkan oleh pemerintah, namun di dalam pelaksanaannya dilapangan masih banyak hambatan yang $d$ temui seperti :

a. Kebijakan sarana hukum dalam penegakan hukum administrasi secara operasional yang dikeluarkan oleh pemerintah terkadang tidak konsisten dengan prinsip-prinsip perlindungan dan penglolaan lingkungan hidup didalam UU No. 32 Tahun 2009 maupun dengan UU yang berkaitan dengan pengelolaan lingkungan hidup lainnya.

b. Terbatasnya aparat penegak hukum yang profesional didalam penegakan hukum lingkungan yang mampu menangani kasus-kasis lingkungn. Selain itu keterbatasan pengetahuan dan pemahaman aspek-aspek lingkungan oleh penegak hukum juga menjadi kendala yang sangat dominan di dalam penegakan hukum administrasi.

c. Fasilitas dan sarana pnunjang yang sangat terbatas (termasuk dana), karena fasilitas dan sarana adalah alat untuk mencapai tujuan penegkan hukum lingkungan.

d. Perizinan. Periziznan adalah salah satu hamabatan yang serig timbul. Dalam pasal 36 UU No. 32 taun 2009 masih 
bisa dilewati begitu saja oleh penguasa, hal ini terjadi karena adanya kerjasama antara perusahan dan instansi terkait yang menangani masalah periziznan.

2. Faktor Eksternal
a. Kurangnya partisipasi masyarakat dalam memberikan aduan mengenai masalah- masalah yang timbul akibat adanya pencemaran dan kerusakan lingkungan kepada pihak yang berweenang seperti Dinas Lingkungn Hidup (DLH) Kota Semarang sebagai instrumen penegakan hukum lingkungan. Hal tersebut dikarenakan kurangnya pengetahuan mayarakat tentang bagaimana prosedur dan mekanisme pelaporan.Kasus

kerusakan lingkungan terkadang dianggap remeh oleh sebagian orang sehingga menyeabkan orang tersebut kurang perduli untuk menjaga lingungan.

b. Sulitnya bertemu dengan pemrakarsa atau pemilik usaha dan/atau kegiatan.

c. Budaya hukum yang buruk juga menjadi salah satu faktor penghambat penegakan hukum lingkungan. Karena di Indonesia korupsi masih

\begin{abstract}
menjadi salah satu hal yang menarik untuk dibahas. Kentalnya budaya korupsi, kolusi dan nepotisme yang terjadi antara perusahaanperusahaan dan pemerintahan yang mencari keuntungan dari dari permaalahan lingkungan. Lobi-lobi illegal antara perusahaan dan pmerintah masih sering terjadi.
\end{abstract}

\section{Peran Hukum Administrasi dalam}

Peran sanksi administrasi dalam penegkan hukum lingungan hidup merupakan suatu sanksi yang di tempuh pertama kali sebagai upaaya preventif dan represif terhadap pelanggaran lingkungan hidup. Penegkan hukum secara preventif danrepresif tersebut dimaksudkan agar masyarakat (pemrakarsa/pemegang usaha) taat terhadap norma hukum lingkungan administrasi tersebut. Bersifat preventif dilkukan melalui pengawasan, sedangkan bersifat represif dilakukan mellui sanksi administrasi.

Sanksi administrasi juga bertujuan sebagai sanksi yang instrumental yaitu pengendalian perbuatan terlarang. Saksi administrasi ditujukan kepada perlindungan kepentingan yang dijaga oleh ketentuan yang dilanggar seperti pelanggaran hukum lingkungan administrasi 
seperti pada PT. Hadi Putra Makmur selaku penanggng jawab kegiatan usaha Guest House Siliwangi (penginapan) yang melakukan pelanggaran terhadap peraturan perundang-undangan dibidang perizinan dan kerusakan lingkungan hidup, bahwa PT. Hadi Putra Mkmur ini tidak melengkapi izin lingkungan sebagaimana tercantum dalam PP Nomor 27 Tahun 2012 tentang izin lingkungan. Bahwa di dalam paksaan pemerintah tersebut PT. Hadi Putra Makmur tersebut diminta untuk segera menyusun dokumen lingkungan hidup berupa DPLH bagi usaha dan/atau kegiatan yang wajib memiliki UKL-UPL.

Sanksi administrasi ini merupakan suatu penegakan yang bisa dikatakan paling efektif dan paling banyak digunakan. Penegakan hukum lingkungan menggunakan sanksi administrasi merupkan suatu langkah pertama yang harus diambil di dalam penegakan hukum lingkungan untuk mencapai suatu pengaturan lingkungan

Fungsi dari penerapan sanksi administrasi tersebut juga bertujuan untuk mengembalikan hak-hak masyarakat yang secara tidak lamgsung dirampas oleh para pemrakarsa atas pelanggaran dan terjadinya kerusakan lingkungan karena proses pembangunan yang tidak sesuai dengan UUPPLH. Fungsi lainya adalah untuk memberikan penegakan hukum yang efektif, konsisten, dan konsekuen terhadap pelanggaran izin dan pecemaran yang dilakukan perusahaan di kota Semarang ini sendiri.

\section{Simpulan}

Penegakan hukum administrasi terhadap kegiatan yang tidak berdampak penting yang belum memiliki dokumen UKL-UPL dalam studi kasus Guest House Siliwangi Semarang oleh DLH Kota Semarang berdasarkan keputusan Walikota Semarang menetapkan untuk mengenakan sanksi administrasi lingkungan hidup berupa sanksi administrasi dengan jenis yang kedua yaitu paksaan pemerintah kepada PT. Hadi Putra Makmur selaku penanggung jawab kegiatan usaha Guest House Siliwangi (penginapan) yang melakukan pelanggaran terhadap peraturan perundang-undangan dibidang perizinan dan kerusakan lingkungan hidup, bahwa PT. Hadi Putra Mkmur ini tidak melengkapi izin lingkungan sebagaimana tercantum dalam PP Nomor 27 Tahun 2012 tentang izin lingkungan. Bahwa di dalam paksaan pemerintah tersebut PT. Hadi Putra Makmur tersebut diminta untuk segera menyusun dokumen lingkungan hidup berupa DPLH bagi usaha dan/atau kegiatan yang wajib memiliki UKL-UPL.

Hambatan yang timbul dalam penegakan hukum administrasi yang dilakukan oleh DLH Kota Semarang terhadap PT. Hadi Putra Makmur disebabkan oleh beberapa faktor internal dan ekstrnal seperti dari terbatasnya aparat penegak hukum yang profesional dalam menegakan 
kasus-kasus lingkungan, kurangnya partisipasi masyarakat dalam memberikan aduan mengenai masalahmasalah yang timbul akibat pelanggaran lingkungan yang disebabkan oleh kurangnya pengetahuan masyarakat tentang bagaimana prosedur dan mekanisme pelaporan, dan yang paling penting adalah buruknya budaya hukum yang sringkali hanya dimanfaatkan oleh kepentingan perusahaan atau pemrakarsa dan pemerintah di dalampenegakan lingkungan.

Peran hukum administrasi dalam penegkan hukum lingungan hidup merupakan suatu sanksi yang di tempuh pertama kali sebagai upaya preventif dan represif terhadap pelanggaran lingkungan hidup. Penegkan hukum secara preventif danrepresif tersebut dimaksudkan agar masyarakat (pemrakarsa/pemegang usaha) taat terhadap norma hukum lingkungan administrasi tersebut. Bersifat preventif dilkukan melalui pengawasan, sedangkan bersifat represif dilakukan melalui sanksi administrasi. Saksi administrasi ditujukan kepada perlindungan kepentingan yang dijaga oleh ketentuan yang dilanggar seperti pelanggaran hukum lingkungan administrasi seperti pada PT. Hadi Putra Makmur selaku penanggng jawab kegiatan usaha Guest House Siliwangi (penginapan) yang melakukan pelanggaran terhadap peraturan perundang-undangan dibidang perizinan dan kerusakan lingkungan hidup

\section{Saran}

Negara Indonesia dikenal dengan negara hukum, dimana pengertian secara sederhananya adalah negara yang menyediakan kekuasaan pemerintahannya didasarkan atas hukum. Maka dari itu diharapkan untuk semua warga negara tidak terkecuali pemerintah harus patuh terhadap hukum. Seperti yang telah kita ketahui akir-akhir ini hukum hanya dijadikan sebgai formalitas dan tameng bagi penguasa saja. Keberlakuan hukum itu sendiri seperti ada namun tiada.

Dalam masalah lingkungan yang terjadi diharapkan pemerintah seperti Dinas Lingkungan Hidup dan pemerintah yang terkait lainnya harus tegas dalam melakukan penegakan pelanggaran di dalam penegakan lingkungan hidup. Pemerintah diharapkan bisa menjadi contoh yang baik bagi masyarakat bukan malah sebaliknya, yauitu mnejadi pelanggar hukum sejati. Hukum seyogyanya harus ditegakan susuai dengan paraturan perundang-undangan.

Dalam hal pembangunan pemrakarsa juga harus patuh terhadap perautran yang telah dibuat. Pemrakarsa dalam melakukan usaha dan/atau kegiatan yang memiliki dampak penting maupu tidak berdampak penting terhadap lingkungan, harus menyusun dokumen UKL-UPL terlebih dahulu sebelum memiliki izin lingkungan (DPLH), agar dampak yang ditimbulkan dapat diminimalisir sedini mungkin.

Masyarakat juga diharapkan dapat berpartisipasi menjaga mengantisipasi maupun dalam penegakan lingkungan apabila 
diketahui di dalam prosesnya terjadi pelanggaran yang dilakukan oleh pemegang usaha dan/atau kegiatan agar tidak terjadi kerusakan lingkungan yang berkepanjangan.

\section{Daftar Pustaka}

\section{Literatur}

Andi Hamzah. 2005. Penegakan Hukum Lingkungan, Jakarta : Sinar Grafika

Danusaputro, Munadjat. 1981. HukumLingkungan. Jakarta : jakarta Binacipta

Hardjasoemantri, Koesnadi. Hukum Tata Lingkungan. Gajah Mada University Press

H. Bachrul Amiq. Sanksi Administrasi Dalam Penegakan Hukum Lingkungan.

Indra Sukma. 2009. Skripsi, Tinjauan Hukum Pelaksanaan Analisis Dampak Lingkungan di Kota Semarang, Fakultas Hukum, Universitas Stikubank, Semarang, 2009.

Muhammad Abdul Kadir, 2004. Hukumdan Penelitian Hukum, PT. Citra AdityaBakti,

Nurmala Sari, Della. 2017 Skripsi, Penegakan Sanksi Adminstrasi Dalam Sengketa Lingkungan Hidup, Fakultas Hukum, Universitas Stikubank, Semarang,

Prahadi, Risma. 2017. Skripsi. Penegakan Hukum Lingkungan Terhadap Kegiatan Berdampak Penting Yang Belum Memiliki Dokumen AMDAL, Fakultas Hukum, Universitas Stikubank, Semarang
Rochmani. 2014.Hukum Lingkungan dan Penegakan Hukum. Semarang: Pustaka Magister

Soemartono, Gatot P. 2004. Hukum Lingkungan Indonesia. Jakarta : Sinar Grafika

Soemarwotto, Otto. 3003.Analisis Mengenai Dampak Lingkungan. Yogyakarta : Gajah Mada University Press

Subagyo, P. Joko.2002. Hukum Lingkungan dan Masalah Penanggulangannya. Jakarta : Rineka Cipta

Spelt N.M, dkk. 1993. Pengantar Hukum Perizinan. Disunting oleh Philipus

M.Hadjon, Yuridika, Surabaya

\section{Perundang-undangan}

1. UU No. 32 Tahun 2009 tentang Perlindungan dan Pengelolaan Lingkungan Hidup

2. Peratiran Pemerintah No. 27 Tahun 2012 tentang Izin Lingkungan

3. Peraturan Menteri No. 16 Tahun 2012 tentang Pedoman Penyusunan Dokumen Lingkungan Hidup.

\section{$\underline{\text { Jurnal }}$}

Dahlia Kusuma Dewi. Jurnal. Izin Lingkungan dalam Kaitannya dengan Penegakan Administrasi Lingkungan dan Pidana Lingkungan Berdasarkan Undang-Undang No. 32 Tahun 2009 tentangPerlindungan dan Pengelolaan Lingkungan Hidup (UUPPLH). Universitas Tjut Nyak Dien 
Fachreza Akbar Hidayat dan Ahmad

Basuki. Jurnal. Perizinan

Lingkungan Hidup dan Pemberian sanksi Bagi pejabat Pemberi Izin.

Fakultas Hukum. Universitas Brawijaya

Helmi. Jurnal. Kedudukan Izin Lingkungan Dalam Sistem Perizinan di Indonesia. Ilmu Hukum, Vol. 2 No. 2

Jaka Kelana. 2017. Jurnal. Peran Hukum Pidana Dalam Penegakan Hukum Lingkungan di Indonesia Fakultas Hukum. Universitas Simatera Utara. Medan

Website

https://materiku86.blongspot.com/201

6/05/pengertian-dan-unsur-unsurlingkungan-hidup.html?m=1 